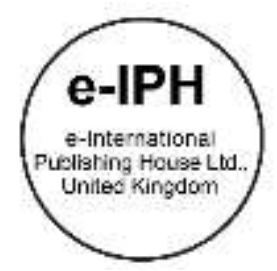

\title{
Food Hygiene at On-Site Premises in Perak and Selangor: Are we ready for self-regulatory practices?
}

\author{
Mazni Saad 1, Mohd Hanafi Azman Ong², Noor Suzana Osman³, Norhidayah Abdullah4 \\ 1 Kulliyyah of Languages and Management, \\ International Islamic University Malaysia, Pagoh Education Hub, KM 1, Jalan Panchor, Pagoh, 84600 Muar, Johor, Malaysia \\ 2Faculty of Computer and Mathematical Sciences, \\ Universiti Teknologi MARA, Segamat, Johor, Malaysia \\ 3 Kulliyyah of Allied Health Sciences, \\ International Islamic University Malaysia, Kuantan Campus, 25200 Kuantan, Pahang, Malaysia \\ ${ }^{4}$ Faculty of Hotel and Tourism Management, \\ Universiti Teknologi MARA, Puncak Alam Campus, Selangor, Malaysia \\ maznisaad@iium.edu.my, napieong@uitm.edu.my,noorsuzana@iium.edu.my,norhi813@salam.uitm.edu.my \\ Tel:+60178787543
}

\begin{abstract}
Safe and hygienic food add value to food intake and prevent undesirable health conditions. Food handlers who are at the forefront of the food service process must monitor and measure the standards of their food hygiene and its preparation and cooking practices. This study investigates how ready food handlers at on-site premises are for self-regulatory practices. Food surface contacts were chosen for investigation via purposive sampling and swab analysis to unravel hidden messages about the level of hygiene standards in the foodservice operation. The findings reveal the existence of contamination across the majority of the selected contact surfaces that could affect the consumers' well-being and quality of life.
\end{abstract}

Keywords: consumer well-being; food hygiene; food surface contact; food handler; the on-site premise

eISSN: 2398-4287 @ 2019. The Authors. Published for AMER ABRA cE-Bs by e-International Publishing House, Ltd., UK. This is an open-access article under the CC BYNC-ND license (http://creativecommons.org/licenses/by-nc-nd/4.0/). Peer-review under responsibility of AMER (Association of Malaysian Environment-Behaviour Researchers), ABRA (Association of Behavioural Researchers on Asians) and cE-Bs (Centre for Environment-Behaviour Studies), Faculty of Architecture, Planning \& Surveying, Universiti Teknologi MARA, Malaysia. DOI: https://doi.org/10.21834/e-bpj.v4i10.1568

\subsection{Introduction}

Everybody needs food and water to grow, stay healthy, and have energy as part of sustaining one's quality of life. Specifically, food with hygienic and safe elements will add value to food intake and prevent undesired health conditions. From a religious perspective, hygienic and safe food is kosher food for the Jews and halal food for the Muslims. Kosher in the Hebrew Bible means "fit" and "appropriate". Halal is also a very crucial concept for all Muslims. The Quran, al Baqarah verse: 173 and 174 states; "O ye who believe! Eat of the good things wherewith We have provided you, and render thanks to Allah if it is (indeed) He Whom ye worship "and "He hath forbidden you only carrion and blood, and swineflesh, and that which hath been immolated to (the name of) any other than Allah. However, he who is driven by necessity, neither caving nor transgressing, it is no sin for him. Lo! Allah is Forgiving, Merciful." Both the Jews and Muslims are only allowed to eat permitted-food according to the guidelines given by their respective holy books. Interestingly, the halal factor is now a trend for the tourism and hospitality industry as many tourists seek a guarantee for clean and safe food. Over the years, the demand for halal food has increased tremendously. The Global Halal Market recorded USD1.4 trillion in 2017 and was projected to reach USD2.6 trillion for 2018 due to the rising Muslim population and increasing availability of these products and services (Report Buyer, 2017).

eISSN: 2398-4287 (C) 2019. The Authors. Published for AMER ABRA cE-Bs by e-International Publishing House, Ltd., UK. This is an open access article under the CC BYNC-ND license (http://creativecommons.org/licenses/by-nc-nd/4.0/). Peer-review under responsibility of AMER (Association of Malaysian Environment-Behaviour Researchers), ABRA (Association of Behavioural Researchers on Asians) and cE-Bs (Centre for Environment-Behaviour Studies), Faculty of Architecture, Planning \& Surveying, Universiti Teknologi MARA, Malaysia.

DOI: https://doi.org/10.21834/e-bpj.v4i10.1568 
In Malaysia, food consumers are protected in accordance with the 1983 Food Act (Act 281). The Act consists of Food Hygiene Regulations 2009, Food Regulations 1985, and Food Regulations 2009 (issuance of health certificate for export of fish and fish products to EU). As practical guidance for the food sector, food standards are made available like ISO 22000:2012 (Food Safety Management), MS1500:2009 (For Halal Food), MS1480 (Food Safety according to Hazard Analysis and Critical Control Points (HACCP)), MS1514 (Good Manufacturing Practice for Food), just to mention a few. Among all, MS1500 is the food safety management system (FSMS) that covers various aspects of Good Manufacturing Practice (GMP) and HACCP. Figure 1 illustrates Malaysia's food safety certification according to three levels: FSMS, HACCP and GMP. These established standards in the food and beverage sector create confidence in the products we consume every day. Other self-voluntarily programs are Good Handling Practices or Good Hygiene Practices (GHP), GMP, and HACCP in food factories.

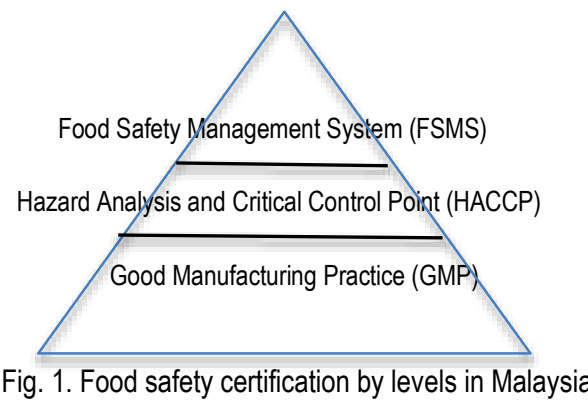

\subsection{Problem Statement}

In $2011,3.52 \%$ out of 98,308 premises inspected were found to be unsanitary and were therefore closed under Section 11, Food Act 1983 (MOH, 2011). A study by Saad, Poh, and Adil (2013) highlighted foodborne issues that are due to food safety practices crucial for community health. Abdul-Mutalib et al. (2012) on the hand reported on the lack of knowledge of food safety practices during preparation and processing of food that violated food safety. Meanwhile, Jeinie, Saad, Sharif, and Nor (2016) discussed the importance of food safety knowledge for biological, chemical, and physical hazards. Food premise inspections are conducted by the Ministry of Health under the Food Quality Control Division. As the food industry is now expanding aggressively, the industry can no longer depend only on enforcement staff from the local health authorities. In October 2018, the Malaysian Department of Statistics reported that the Industrial Production Index (IPI) increased by 4.2 per cent compared to the same month of the previous year. The IPI is mainly supported by manufacturing where food, beverage and tobacco contributed 2.6 per cent of the overall manufacturing indices.

Food business operators, therefore, opt for a self-regulatory procedure and take full responsibility for monitoring the hygiene standards of their operation. This procedure aligns with the hygiene inspection checklist which is now widely implemented particularly in the operation of a kitchen in schools. Kitchen managers use the checklist to check if utensils are clean and safe for use. Professional kitchens of small and medium-sized businesses such as catering, mobile food operators, and restaurants also use this self-monitoring system as recommended in HACCP. The bureaucratic and product-specific HACCP system is scientifically-based and follows a systematic concept to determine specific sources of hazards in order to control and ensure the safety of foodstuff. HACCP also requires a set of practices for incoming goods inspection, temperature monitoring, pest control, staff training, and hygiene plan. The hygiene or cleaning plans consist of disinfection measures for all operational areas including sales, production, and storerooms. This in-house practice is not only cost-effective but also flexible for integration into an existing quality management system. As such, its good practices must be documented, and the outcomes recorded and checked at several intervals as a way of measuring continuous improvement.

The checklist also includes a record of what is cleaned, how frequent, what with, by whom, how, and when for traceability purposes. Despite transparency in record keeping, there is no certainty that the food service establishment is actually carrying out self-monitoring adequately. Similarly, attending a compulsory food handling course or getting a typhoid injection would guarantee that a food operator is competent in conducting self-regulatory checks.

\subsection{Purpose and Objectives of the Study}

The main purpose of this study is to find out if Malaysian food handlers at on-site premises are ready for self-regulatory practices. To achieve this, it assumes that food handlers in government-controlled food establishments have sufficient knowledge and awareness of good hygiene and practices. Information on food contact surfaces was therefore obtained from these sites to gauge the status of their food hygiene practices and their level of readiness for self-regulatory inspections.

\subsection{Literature Review}

\subsection{Food Contact Surface}

The food contact surface is a familiar source of foodborne viruses. The improper handling practices of these surfaces during the cleaning or handling of food may cause food contamination that could potentially be risky to public health. This is especially crucial when the spread of foodborne diseases is involved. Food contact surfaces refer to surfaces (e.g. of knives, tables, cutting boards and food handlers) that consist of pathogenic microorganisms that are in direct contact with food during the ordinary course of operation. These 
food contact surfaces, as well as the food handlers' hands, have been described as a potential vehicle for the transfer of pathogen (Blackburn, 2003). According to Begani et al. (2012), there are two procedures of cleaning and sanitation in an operation that can reduce the number of pathogenic and food spoilage microorganism to acceptable levels.

Besides that, the nature of the contact surface may also have an impact on contamination levels of food with microorganisms (Nhlapo et al., 2014). Unlike smooth surfaces which are easier to clean, cracks, splinters, scratches, and distorted surfaces which usually hamper proper cleaning and sanitising instead provide shelter for microorganisms to thrive. Frequent sanitation is, therefore, an effective way of controlling and ensuring the microbiological safety of foodstuffs (Knechtges, 2012). Food contact surfaces have also been shown to be a possible transmission vehicle for foodborne illnesses. A study by Nhlapo et al. (2014) on the preparation of surfaces suggest that although a surface may not be a source of contamination, the chance for cross-contamination among surfaces may exist because of a lack of surface separation and shortcomings in cleaning management.

\subsection{Pathogenic Bacteria}

The Escherichia coli (E. coli), Salmonella, Shigella, and Staphylococcus are the most common microbiological hazards that cause food poisoning as these bacteria will release toxins that cause gastroenteritis (Loukieh et al., 2018). Human hands contribute the most to foodborne illnesses since they are in regular contact with the surrounding environment, while the pathogens can reach the mucous membranes in the mouth, nose, eyes, and genitals (Hawker et al., 2012). Findings from a study by Ayçiçek et al., (2004), show that poor hand hygiene might contribute to high levels of $S$. aureus and $E$. coli on the hands of food handlers. Besides that, kitchen utensils also present possible factors that lead to bacterial contamination of their surfaces.

A study by Baghapour et al., (2014) found samples taken from the surface of cutting boards, tables and hands of food handlers with an acceptable bacterial and coliform contamination level. However, another study by Nhlapo et al., (2014) reported that preparation surfaces enumerated the highest counts of total coliforms, E. coli, and S. aureus, with aprons yielding the highest count of yeast and moulds, while hands had the lowest count of these organisms.

Pathogenic bacteria can be transmitted at any stage of food preparation, including contamination at the farm during slaughtering where meat has been in contact with animal intestines and fur or skin, as well as in the kitchen especially during food preparation due to improper handling (European Food Safety Authority, 2014). Lack of personal hygiene among the food handlers, unclean environment and water supply are known factors that contribute to foodborne illnesses (Meftahuddin, 2002). However, the most common source of contamination would be the food handlers themselves because they can spread pathogenic organisms via a faecal-oral route or skin lesions and the use of dirty kitchen utensils or kitchen counters (Linscott, 2011).

\subsection{Methodology}

In this study, the on-site premises' readiness for self-regulatory practices among the food handlers is investigated by using the food contact surface as an indicator that determines the effectiveness of both the cleaning and sanitisation procedures. In Selangor and Perak, this study identified 17 government-controlled on site-premises. Based on purposive sampling, the investigation of food contact surfaces was done at six government-controlled on-site premises as recommended by the Malaysian Ministry of Health.

\subsection{Swab Analysis Procedures}

There are two types of swab methods; conventional and unconventional. The conventional method is recommended for application in field studies or food safety management protocols in the industry as it can detect pathogenic bacteria (ISO 18593, 2004). A sterile cotton swab with an applicator stick for releasing microorganisms from the surface is generally used in the conventional swabbing procedure (Pérez-Rodríguez et al., 2008), while an unconventional swab uses a calcium alginate swab bud which dissolves directly in the culture medium and is much more accessible than the conventional service method (Miller, 1996). As for this study, a Rida@count swab analysis was used to test the presence of protein on food contact surfaces that have been cleaned.

In this microbial investigation, the food contact surfaces taken for sampling were those in the critical areas of the intermediate and final processes of the food service operation as suggested by "a Guide to Environmental Microbiological Testing for the Food Industry" (2008). It was suggested that a greater emphasis should be given to areas which involve dirtier activities, or in dirty activity areas that are in close relative proximity to clean areas which are often wet, open drain areas, and areas that have a high level of staff activity.

\subsection{Material and Method}

Food contact surfaces in this study refers to the dining table top, cutting knife, food serving tray, cooking pot, and spatula. Coliforms were also isolated from the same sample source. The swabbing of these surfaces was done using the Rida@count hygiene monitoring of sanitation programs. Microbial colonies were counted as Colony Forming Units (CFU)/cm² that were computed in $\log _{10} \mathrm{CFU} / \mathrm{cm}^{2}$. The Pearson Chi-Square was used to determine the microbial colonies at six locations in the two big states of Peninsular Malaysia. This study has adopted techniques used by Saad et al. (2016) in which the RIDA Count $₫$ in addition to the Colilert Test was used to determine the cleanliness of food contact surfaces after regular cleaning. Their results show that all food contact surfaces (dining table tops, food trays, cooking pots and kitchen faucets) had the highest coliform contamination. The same technique was therefore applied in this study to detect possible pathogen microorganisms that would reflect the food hygiene practices of on-site premises. 


\subsection{Findings}

In this study, the Chi-Square analysis was performed to access the existence of total coliforms of contact surfaces taken from six selected Institutional Foodservice Establishments. This analysis was used since the data for both variables (i.e. Existence of total coliforms vs Institutional Foodservice Establishments) were categorical data (Field, 2009). In this study, the Existence of total coliforms was categorised as two categories; Exist or Don't Exist, whereas the Institutional Foodservice Establishments were categorised into six categories to reflect the six targeted locations of the Institutional Foodservice Establishments in Malaysia.

The sample size for this study can be considered as relatively small, as it consists of three replications for each food service institution. Hence, a combination of the Likelihood Ratio Test and Fisher's Exact Test were used. According to Field (2009), Agresti (2007), and Daniel (1990), both tests can be used for small sample sizes in the categorical data analysis since it produces a more consistent analysis (i.e. not too much deviant) from the Chi-Square distribution.

Table 1. Summary Result of Likelihood Ratio and Fisher's Exact Tests on Existence of Total Coliforms of selected Contact Surfaces across Institutional Foodservice Establishments

\begin{tabular}{lll}
\multicolumn{4}{c}{ Lontact Surface } & Likelihood Ratio Test & Fisher's Exact Test \\
\hline Dining Table Top & $8.739(p=.120)$ & $6.548(p=.118)$ \\
Cutting Knife & $8.739(p=.120)$ & $6.548(p=.118)$ \\
Food Serving Tray & $15.276^{*}(p=.009)$ & $9.893^{*}(p=.026)$ \\
Cooking Pots & $15.276^{*}(p=.009)$ & $9.893^{*}(p=.026)$ \\
Spatula & $20.238^{*}(p=.001)$ & $12.833^{*}(p=.006)$ \\
& & \\
\hline Note: $p=$ Probability value; Degree of Freedom $=(\text { row }-1)^{*}($ column -1$)=5^{*} 1=5 ;{ }^{*} p<.05$.
\end{tabular}

Based on Table 1, it can be concluded that total coliforms existed on the Dining Table Top and Cutting Knife contact surface across six selected Institutional Foodservice Establishments (refer to Figures $2 \& 3$ ). However, the result of the analysis for both contact surfaces was not statistically significant (Dining Table Top \& Cutting Knife: Likelihood Ratio: 8.739, $p=.120$; Fisher's Exact Test: $6.548, p=.118$ ). However, as for Food Serving Tray, Cooking Pot, and Spatula, the analysis indicates that there was a significant difference in terms of the existence of total coliforms across the six selected Institutional Foodservice Establishments, since the Likelihood Ratio Test, as well as the Fisher's Exact Test, were significant at $95 \%$ confidence level (i.e. all p-values <.05).

Regarding the existence of this microbe at the Food Serving Tray contact surface, Figure 4 indicates that total coliforms existed at X5, X4, and X3 Institutional Foodservice Establishments, whereas X6 Institutional Foodservice Establishment indicates that the microbe could be assumed as non-existent based on the three replication samples. However, for X2 and X1 Institutional Foodservice Establishments, the existence of total coliforms could be described as mild since around one to two replication samples indicated the existence of this microbe. As for the existence of the total coliforms at the Cooking Pot contact surface, Figure 5 confirms that the microbe existed throughout the Cooking Pots of X4, X5, and X6 Institutional Foodservice Establishments, but not at X1 Institutional Foodservice Establishment. The analysis also indicates that total coliforms were at a mild level for X3 and X2 Institutional Foodservice Establishments. Concerning the Spatula contact surface, Figure 6 confirms that this microbe existed on all Spatula contact surfaces of X3, X4, and X6 Institutional Foodservice Establishments. Nevertheless, the existence of this microbe can be described as null for X6 and X2 Institutional Foodservice Establishments. Also, X1 Institutional Foodservice Establishment indicates that the existence of this microbe was at a mild level since only two replication samples indicated the existence of this microbe.

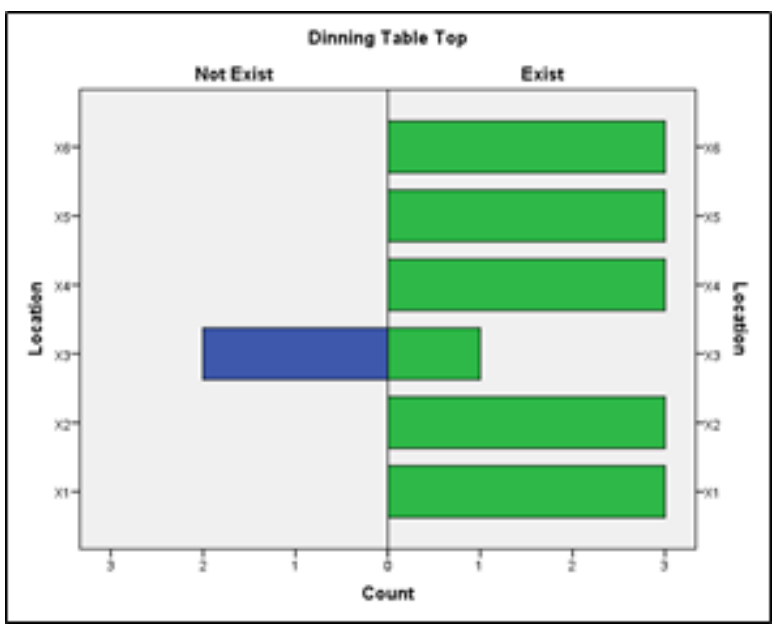

Figure 2: Cross-tabulation Analysis of Existence of total coliforms at Dining Table Top across Six Selected Institutional Foodservice Establishments

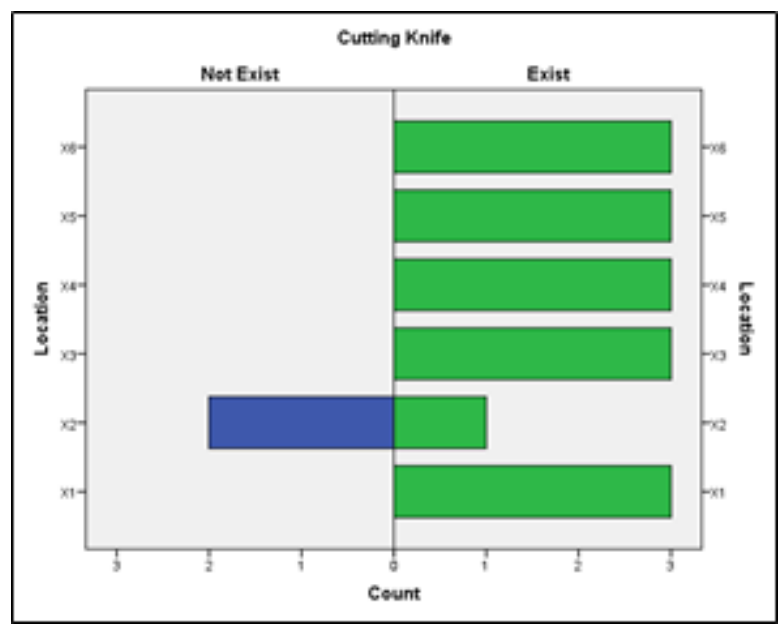

Figure 3: Cross-tabulation Analysis of Existence of total coliforms at Cutting Knife across Six Selected Institutional Foodservice Establishments 


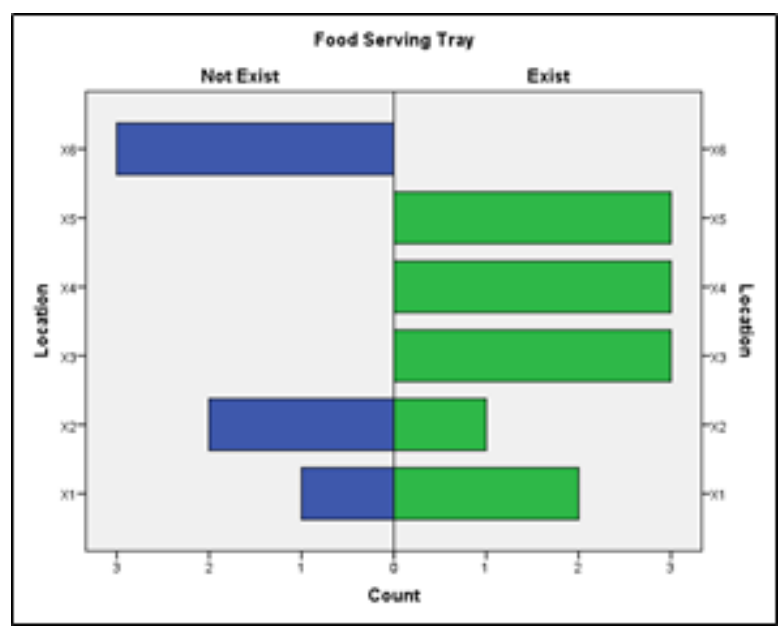

Figure 4: Cross-tabulation Analysis of Existence of total coliforms at Food Serving Tray Top across Six Selected Institutional Foodservice Establishments

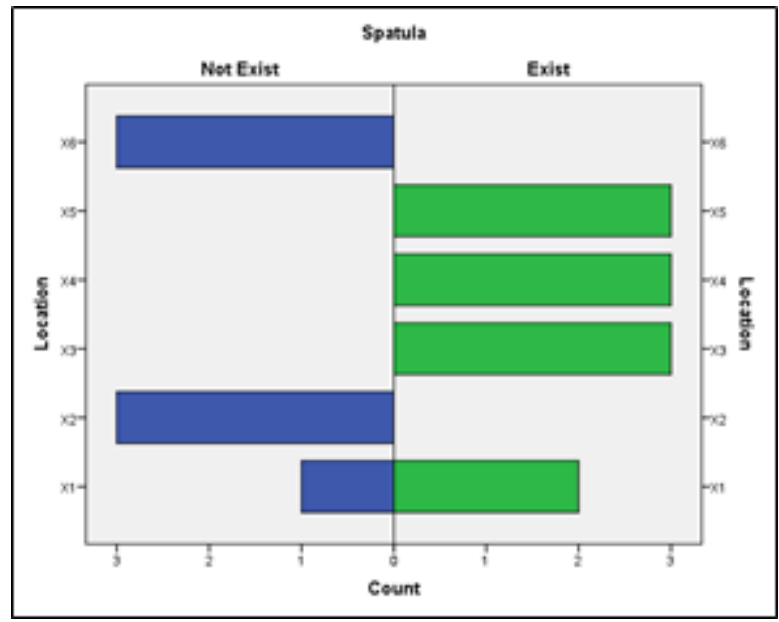

Figure 6: Cross-tabulation Analysis of Existence of total coliforms at Spatula across Six Selected Institutional Foodservice Establishments

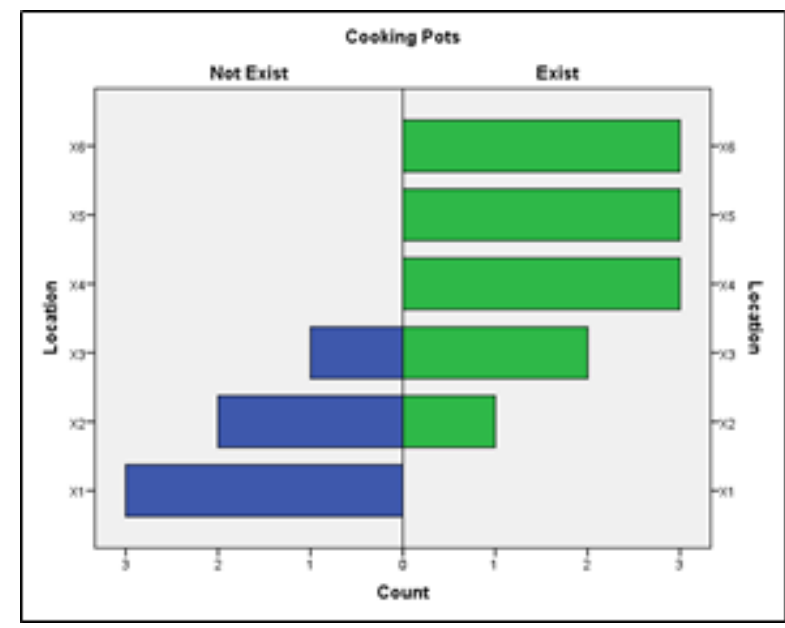

Figure 5: Cross-tabulation Analysis of Existence of total coliforms at Cooking Pots Top across Six Selected Institutional Foodservice Establishments

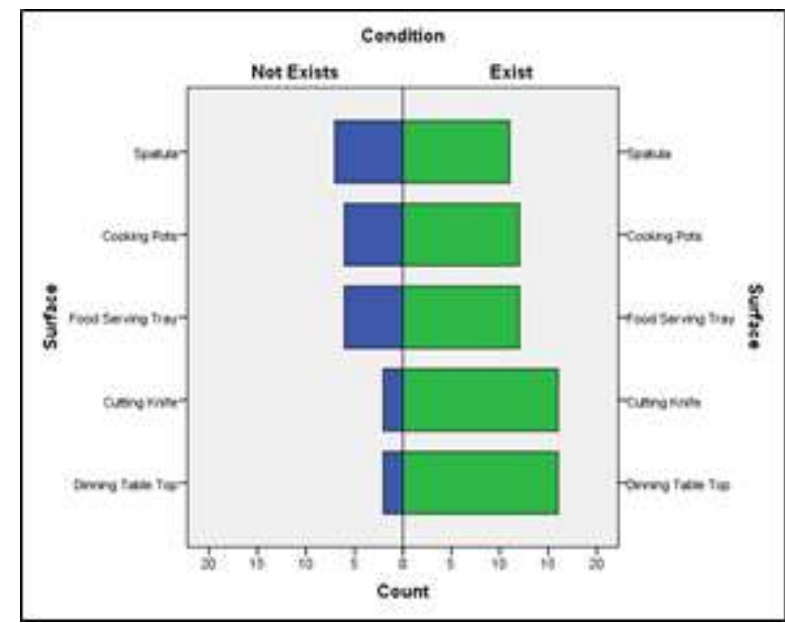

Figure 7: Cross-tabulation Analysis of Existence of total coliforms and Contact Surface

As for determining the significant differences about the existence of total coliforms across selected five contact surface by combining all the six selected Institutional Foodservice Establishments data, Table 2 indicates that the existence of total coliforms at these selected five contact surface as shown by the non- statistically significant results (Likelihood Ratio: 7.302, $p=.121$; Fisher's Exact Test: $6.779, p$ $=.133$ ). By referring to the Cross-tabulation analysis (i.e. Figure 7), the analysis indicated that total coliforms existed on the majority of the contact surfaces.

Table 2. Summary Result of Likelihood Ratio and Fisher's Exact Tests Existence of Total Coliforms of selected Contact Surfaces across Institutional

\begin{tabular}{lc}
\multicolumn{2}{c}{ Foodservice Establishments } \\
\hline Likelihood Ratio Test & Fisher's Exact Test \\
\hline $7.302(p=.121)$ & $6.779(p=.133)$ \\
\hline Note: $p=$ Probability value; Degree of Freedom $=(\text { row }-1)^{*}($ column -1$)=4^{*} 1=4 ;{ }^{*} p<.05$.
\end{tabular}

\subsection{Discussion}

This research provides significant information on the total coliform contamination level of Dining Table, Cutting Knife, Food Serving Tray, Cooking Pot and Spatula contact surfaces of six selected Institutional Foodservice Establishments. The results attained from this study should be given urgent attention and serious intervention from all parties concerned. Coliforms exist on the surfaces of Dining Table and 
Cutting Knife $(p>0.05)$ whereas the range of 'not exist to exist' coliforms is found on the Food Serving Tray, Cooking Pot and Spatula surfaces across the six Institutional Foodservice Establishments studied. In total, coliform contamination is found on the majority of the selected contact surfaces studied, although, between the Institutional Foodservice Establishments, the contamination is not significant.

Above all, the results show a significantly high total coliforms count on the surfaces of Food Serving Trays, Cooking Pots and Spatulas. Such results confirm the transfer of pathogenic microorganisms including coliform from these food contact surfaces to food service during the potential occurrence of cross-contamination. If food is not handled correctly, cross-contamination may lead to foodborne disease outbreaks, which will impact consumers' health and contribute to substantial economic consequences for nations. The existence of coliform indicates a critical need for a vast improvement in safe food handling practices at foodservice establishments. The pathogenic microorganism found on food-contact surfaces increases the risk of cross-contamination into the food offered to the public.

The significant presence of coliforms on food contact surfaces of all the Institutional Foodservice Establishments reported in this study clearly shows that coliforms are present everywhere in the kitchen especially considering that a kitchen is well equipped with a great variety of utensils and equipment. The existence of Coliform is associated with secondary contamination which is caused by secondary processing and poor personal hygiene, as well as the inadequate sanitisation of surfaces or equipment or an ineffective sanitation program (Ali \& Immanuel, 2017; Nhlapo et al., 2014). Furthermore, coliforms, including E. coli are microorganisms found in the intestinal tract of humans and animals.

The existence of microorganisms in food generally indicates faecal contamination (Pepper \& Gerba, 2009). It is also generally agreed that there is a relationship between food contact surfaces and food handlers' hands, where their hands are considered as a significant vehicle for pathogens (Gorman et al., 2002). Contaminated food surfaces significantly contribute to cross-infection and a high-risk transfer of pathogenic microbial into food. Hence, food handlers can help minimise contamination if they know good hygiene practices which they can gain by attending training modules designed by the local authorities. It has been proven that food handlers who continuously receive training show better hygiene awareness and food safety handling practices than those who do not.

The Institutional Foodservice Establishments selected for this study operate in a relatively rural area where possible environmental contamination from birds, rodents, flies and cockroaches can be very high. According to Nielsen et al. (2004), wild birds and rodents found in rural areas contain a significant amount of toxin-producing pathogen. Apart from that, Nhlapo et al. (2014) added that the usage of contaminated water and shortcomings in surface sanitation methods that include incorrect detergent to water dilution ratio or inadequate contact time, as well as lack of proper kitchen facilities and ventilation might also contribute to contamination of food contact surfaces. Therefore, food contact surfaces need to be thoroughly cleaned and sanitised to reduce the number and type of potential pathogens. Frequent and proper cleaning and disinfection positively control microbiological safety.

\subsection{Limitation of Study}

One of the obvious limitations of this study is that it did not cover the big cooking pots inside the kitchen as they were all in use during the visit.

\subsection{Conclusion and Recommendations}

This study has used crucial data obtained from food contact surfaces of on-site premises to translate several issues relating to food handlers' competency and readiness for self-regulatory monitoring of their food-hygiene practices and standards. The study concludes that food contact surfaces are the most likely vehicle for the transmission of contaminated food and infectious diseases in our world today. With the presence of contamination on most of the contact surfaces studied and the high risks placed on public health and safety resulting from cross-contamination to food service, this study highlights the need for higher food handling practices and standards as well as continuous training and upgrading of relevant skills for those involved in the food industry.

This study suggests that food handlers adopt proper cleaning practices in both the kitchen and dining hall. Cooking and preparation utensils like the dining table tops, cutting knives, food serving trays, cooking pots, and spatulas must be cleaned immediately after use as leftover or spilled food for instance will invite flies, ants, birds, and pests which are also carriers of foodborne diseases. Furthermore, the study recommends the application of a simple scientific tool to ensure accuracy and efficiency in the measurement of hygiene and sanitisation, while all the results should also be recorded and traceable for the Health Ministry's audit inspection. At the same time, field studies are encouraged to compare the tool used in this study with other similar tools so that foodservice operators have a range of choices at their disposal. As the Malaysian government is encouraging a self-monitoring food system at schools, programs providing food to our children would benefit from the hygiene standards and practices expounded in this study. The investigation of self-regulatory hygiene practices with accurate results is therefore vital for the future of food establishments and the food handlers' profession in the industry.

\section{References}

A Guide to Environmental Microbiological Testing for the Food Industry" (2008). http://microgenbioproducts.com/wp-content/uploads/sites/8/2016/02/Path-Chek-Guideto-Environmental-Monitoring_09.05.08-_9_.pdf 
Abdul Mutalib, N. A., Abdul Rashid, M. F., Mustafa, S., Amin Nordin, S., Hamat, R. A., \& Osman, M. (2012). Knowledge, attitude and practices regarding food hygiene and sanitation of food handlers in Kuala Pilah, Malaysia. Food Control, 27(2), 289-293.

Ali, A. A., \& Immanuel, G. (2017). Assessment of Hygienic Practices and Microbiological Quality of Food in an Institutional Food Service Establishment J Food Process Technol 2017, 8:8. DOI: 10.4172/2157-7110.1000685

Ayçiçek, H., Aydoğan, H., Küçükkaraaslan, A., Baysallar, M., \& Başustaoğlu, A. C. (2004). Assessment of the Bacterial Contamination on Hands of Hospital Food Handlers. Food Control, 15(4), 253-259. doi:10.1016/s0956-7135(03)00064-1

Baghapour, M.A., Mazloomi, S.M., Azizi, K., Sefidkar, R. (2015). Microbiological Quality of Food Contact Surfaces in a Hospital Kitchen in Shiraz, Iran, 2014. J Health Sci surveillance System, 3(4), 128-132.

Begani, R.K., Tombe, B., \& Polong, T. (2012). The effectiveness of Cleaning and Sanitation of Food Contact Surfaces in the PNG Fish Canning Industry. Contemporary PNG Studies: DWU Research Journal, 16, 68-82.

Blackburn, C.W. (2003). Microbiological Analysis and Food Safety Management: GMP and HACCP systems. In: McMeekin TA, editor. Detecting Pathogens in Food. Cambridge: Woodhead Publishing Limited, 3-17.

Department of Statistics Malaysia (2018). Press Release Economic Census 2016: Tourism Statistics

Department of Statistics Malaysia (2018). Release series 187/2018.

European Food Safety Authority. (2014) Foodborne Zoonotic Diseases. Retrieved December 12, 2018, from https://www.efsa.europa.eu/en/topics/topic/food-bornezoonotic-diseases.

Field, A. (2009). Discovering Statistics using SPSS (3rd Edition). London: Sage Publications

Food Act, Laws of Malaysia: Food Act and Regulations, 9th ed. Kuala Lumpur: MDC Publishers Printers, 1983.

Gorman R, Bloomfield, S. \& Adley, C.C. (2002). A study of cross-contamination of food-borne pathogens in the domestic kitchen in the Republic of Ireland. International Journal of Food Microbiology, 76(1-2), 143-150.

Hawker, J., Begg, N., Blair, L., Reintjes, R., Weinberg, J., \& Ekdahl, K. (2012). Section 2: Common topics. Communicable Disease Control and Health Protection Handbook. John Wiley \& Sons, Ltd. P. 17-57. https://doi.org/10.1002/9781444346961.ch2

Ipi Grew 4.9pct In August, Says Statistics Dept. (n.d.). Retrieved from https://sg.finance.yahoo.com/news/ipi-grew-4-9pct-august-052412718.html

ISO 18593:2004. Microbiology of Food and Animal Feeding Stuffs -- Horizontal Methods for Sampling Techniques from Surfaces Using Contact Plates and Swabs. Retrieved on $21^{\text {st }}$ December 2018 from https://www.iso.org/standard/39849.html.

Jeinie, M. H., Saad, M., Sharif, M. S. M., \& Nor, N. M. (2016). Hygiene practices and food safety knowledge for biological, chemical and physical hazards. Social Sciences, 11(19), 4633-4637.

Knechtges, P.L. (2012). Food Safety: Theory and Practice. Burlington: Jones \& Bartlett Learning. ISBN-13: 9780763785567

Linscott, A.J. (2011). Food-borne IIInesses. Clinical Microbiology Newsletter, 33 (6), 41-45. https://doi.org/10.1016/j.clinmicnews.2011.02.004

Loukieh, M., Mouannes, E., Abou Jaoudeh, C., Hanna Wakim, L., Fancello, F., \& Bou Zeidan, M. (2018). Street Foods in Beirut City: An Assessment of the Food Safety Practices and of the Microbiological Quality. Journal of Food Safety, 38(3), e12455. doi:10.1111/jfs. 12455

Nhlapo, N., R.J.K, Lues., \& Groenewald, W.H. (2014). Microbial Counts of Food Contact Surfaces at Schools Depending on A Feeding Scheme. South Africa Journal of Science, 110(11/12), Art. \#2013-0351, 1-5. http://dx.doi.org/10.1590/ sajs.2014/20130351

Nielsen, E. M., Marianne N. Skov, M. N., Madsen, J.J., Lodal, J., Jørgen Brøchner Jespersen, J.B \& Dorte L. (2004). Verocytotoxin-Producing Escherichia coli in wild birds and rodents in close proximity to farms. Applied and Environmental Microbiology, 6944-6947.

Meftahuddin, T. (2002). Review of the Trends and Causes of Food Borne Outbreaks in Malaysia from 1988 to 1997. Med J Malaysia, 57(1):70-79.

Miller, A. 1996. Wooden and Polyethylene Cutting Boards: Potential for the Attachment and Removal of Bacteria from Ground Beef. J. Food Protect, 59, 854-859. https://doi.org/10.4315/0362-028X-59.8.854

MOH. (2011). Annual Report. Planning Division, Health Informatics Centre, Ministry of Health, Malaysia. Downloaded from www.moh.gov.my on 12/12/2018.

Pepper, I.L., \& Gerba, C.P. (2009). Environmental Microbiology. 2nd Ed. Burington, MA: Elsevier, 173-189.

Pérez-Rodríguez, F., Valero, A., Carraso, E., Garcia, R.M., \& Zurera, G. (2008). Understanding and Modelling Bacterial Transfer to Foods: A Review. Trends Food Sci. Technology, 19, 131-144. https://doi.org/10.1016/j.tifs.2007.08.003

Report Buyer (2017). Halal Market Size, forecast and Trend Analysis, 2014 to 2024, December 2017, 65 pages. https://www.reportbuyer.com/product/5205107

Saad, M., See, T. P., \& Adil, M. A. M. (2013). Hygiene practices of food handlers at Malaysian government institutions training centers. Procedia-Social and Behavioural Sciences, 85, 118-127.

Saad, M., Toh, P.S., Foong Abdullah, M.F., \& Md Nor, N. (2016). Enhancing Regular Monitoring of Food-Contact Surface Hygiene with Rapid Microbial Kits. Asian Journal of Behavioural Studies (AjBeS), 3(11), 75-83. http://dx.doi.org/10.21834/ajbes.v3i11.103 